\title{
Use of attenuated total reflectance fourier transform infrared spectroscopy as a tool to determine effect of hot air-drying on yield (\%) of chitin from crab integument
}

\author{
T Khumaloa, AV Rane ${ }^{b}$, MT Pandurangan', K Kanny ${ }^{\mathrm{d} *}$
}

\author{
Composite Research Group, Department of Mechanical Engineering, Faculty of Engineering and Built Environment, Durban University of \\ Technology, Durban 4000, South Africa

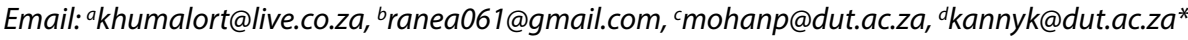

\begin{abstract}
Washing, hot air drying, mechanical grinding, and chemical treatments are used to extract chitin from the integument of crustaceans (crabs). Variable drying times are documented in the literature, but none of the publications correlate drying time to the percent yield of chitin from crab integument, therefore this investigation. The effects of hot air-drying duration on the percent yield of chitin from Ocypode Ryderi (Pink Ghost Crab) (found along the east coast of South Africa) are investigated in this study. The impact of hot air drying on intermolecular changes inside the crab integument was investigated. Using an Attenuated Total Reflectance Fourier Transform Infrared Spectroscopy (ATR-FTIR Spectroscopy), the intermolecular interactions occurring within the crab integument with respect to hot air-drying period were observed. To cover a study gap, crab integument was dried at $0 \mathrm{~h}, 1 \mathrm{~h}, 2 \mathrm{~h}, 3 \mathrm{~h}, 4 \mathrm{~h}, 5 \mathrm{~h}, 6 \mathrm{~h}, 7 \mathrm{~h}, 8 \mathrm{~h}, 9 \mathrm{~h}, 10$ $\mathrm{h}, 11 \mathrm{~h}$, and $12 \mathrm{~h}$ and extracted chitin at $0 \mathrm{~h}, 1 \mathrm{~h}, 2 \mathrm{~h}, 3 \mathrm{~h}, 4 \mathrm{~h}, 5 \mathrm{~h}, 6 \mathrm{~h}, 7 \mathrm{~h}, 8 \mathrm{~h}, 9 \mathrm{~h}, 10 \mathrm{~h}, 11 \mathrm{~h}$, and $12 \mathrm{~h}$. The highest chitin output was found after 12 hours of hot air drying.
\end{abstract}

Keywords: ATR-FTIR Spectroscopy, Hot air-drying, Crab integument, Chitin, \%Yield

\section{Introduction}

Crustacean integuments are the most prevalent source of chitin, and its availability, biodegradability, biocompatibility, and nontoxicity make its application very appealing (Amalraj et al., 2020; Kumari and Kishor, 2020). Crabs are members of the crustacean subphylum. The crab integument is composed of two layers: the outer layer (epicuticle, exocuticle, and endocuticle) and the membranous interior layer. Figure 1 depicts the gross morphology of the crab integument. Understanding gross morphology is essential for gaining a good image of the intermolecular alterations occurring inside the crab integument during hot air drying. A crab's integument is made up of two layers: an exterior calcified layer (M1) and an interior membranous layer (M2). Understanding gross morphology is important to have a clear picture of the intermolecular changes taking place within the crab integument upon hot air-drying.

M1 is further subdivided into epicuticle, exocuticle, and endocuticle - epicuticle is the outermost and thinnest layer, consisting of tanned lipoprotein impregnated with calcium salts - exocuticle immediately underlines the epicuticle and is composed of stacked chitin-protein fibers - endocuticle is the thickest and most heavily

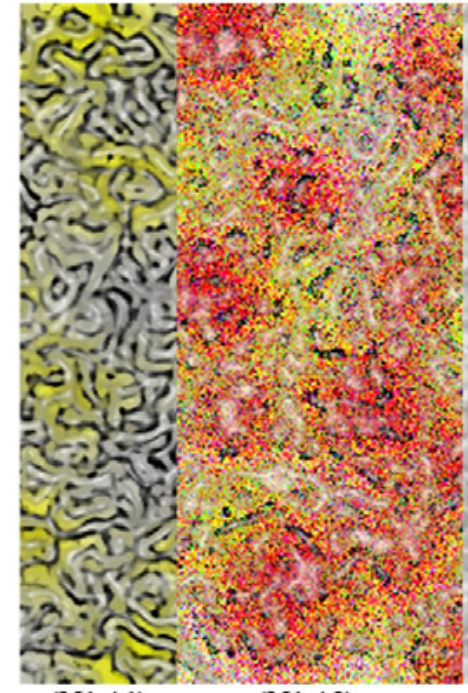

(M1-A1)
(M1-A2)

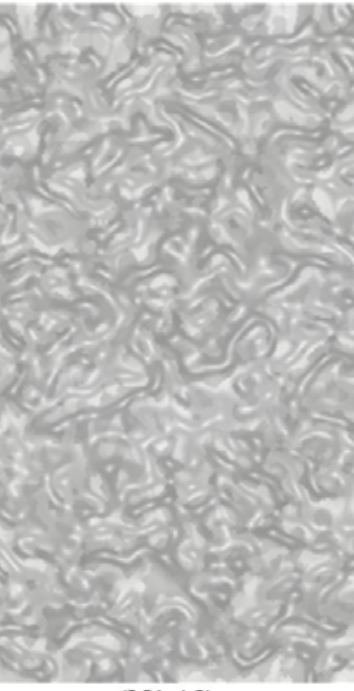

(M1-A3)

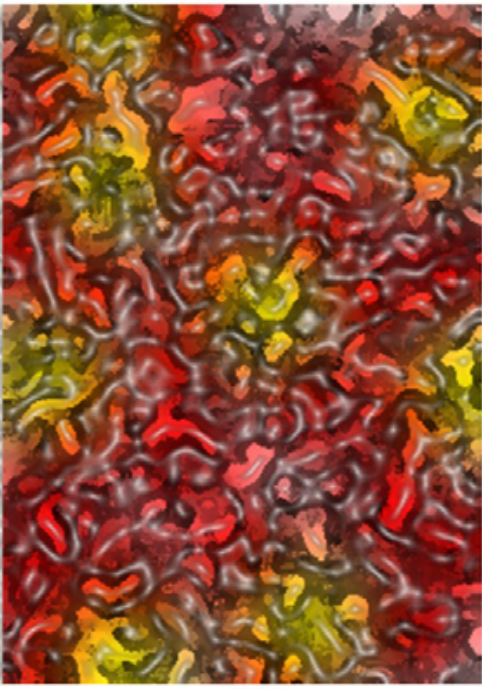

(M2)

Figure 1: Schematic representation of a crab integument's gross morphology (M1-exterior layer which consists of M1-A1-epicuticle, M1-A2-exocuticle, M1-A3-endocuticle and M2-interior layer) 
calcified layer. M2 is made up of chitin (chitin-rich region) and protein but no minerals. Chitin is found in the exocuticle, endocuticle of M1 and M2 of crab integument, according to available reports; consequently, these layers are of interest for extracting chitin from crab integument (Roer and Dillaman, 1984). The crab integument was washed and cleaned with water, then dried at room temperature, hot air dried, mechanically ground, and chemically treated for chitin extraction (Abdou et al., 2008; Cuong et al., 2016; Fan et al., 2008; Hisham et al., 2021; Kumari et al., 2015; Ngoc Cuong et al., 2016; Suenaga and Osada, 2019). Cleaning with water removes the crab's internal organs (Abdou et al., 2008; Cuong et al., 2016; Hisham et al., 2021; Kumari et al., 2015; Pyar Aung et al., 2018). Drying at room temperature is used to remove surface water from the crab integument (Abdou et al., 2008; Kumari et al., 2015; Pyar Aung et al., 2018). Hot air drying is used to eliminate moisture from the gross morphology of a crab integument (Chen et al., 2014; Cuong et al., 2016; Hisham et al., 2021; Koilparambil et al., 2014). The most typical chemical treatments employed in the extraction of chitin from a crab integument are de-mineralization with an acid and de-proteinization with a base (Abdou et al., 2008; Cuong et al., 2016; Fan et al., 2008; Hisham et al., 2021; Kumari et al., 2015; Suenaga et al., 2016; Suenaga and Osada, 2019). As previously stated, hot-air drying of crab integument is required before to mechanical grinding and chemical treatments. The temperature and time of the drying process varied according to the literature reviewed. Koilparambil et al dried shrimp integument for 4 days at $65^{\circ} \mathrm{C}$, Hisham et al dried squid pens for 8 hours at $80^{\circ} \mathrm{C}$ before usage, and Chen et al dried crab shell powder for 24 hours at $60^{\circ} \mathrm{C}$ (Hisham et al., 2021; Koilparambil et al., 2014, Chen et al., 2014). However, the influence of drying durations on chitin output was not described in the literature reviewed. In general, drying is the process of transforming a semi-solid or liquid into a solid by evaporation through the application of heat — this occurs by causing vaporization of the liquid in the specimen when heat is applied (Mujumdar and Devahastin, 2016). Wet solids lose moisture through evaporation from the saturated surface of the solid, which gradually reduces the area of the saturated surface and eventually removes moisture from the interior of the solid. Fundamentally, drying entails the transmission of heat to evaporate the liquid, as well as the transfer of mass as vapors from the surface and vapors within the solid (Green and Perry, 2007). However, drying a complex macromolecular structure includes a number of phase transitions that rely on the temperature and duration of drying and is not the same as solid-liquid drying. The integument of crabs is a complex structure composed of minerals, proteins, and chitin. As a result, examining the effect of hot air-drying on crab integument in terms of percent yield of chitin is an intriguing topic of study. To the best of our knowledge and based on a review of the literature, the effect of hot air-drying on the extraction process of chitin from crab integument has not been recorded. As a result, in this publication, we concentrate on the constant temperature and varying hot airdrying periods to which the crab integuments were subjected prior to mechanical grinding and chemical treatments for chitin extraction. Based on previous research in our group (Rane et al., 2021, 2019) on ATR-FTIR Spectroscopy in analyzing interactions and interfacial characterizations in polymer composites, we were successful in attempting to correlate ATR-FTIR spectra with phase transitions occurring within the hot air-dried crab integument, relating them to the percent yield of chitin and purity.

\section{Materials and methods}

\subsection{Materials}

Ocypode Ryderi (Pink Ghost Crab) was obtained (R130/kg) from Durban's Sea Food Market. The water used to wash and clean the crabs came from a Millipore unit installed at the Composite Research Group Laboratory. Hydrochloric acid ( $\mathrm{HCl}$ ) and sodium hydroxide $(\mathrm{NaOH})$ were obtained from Radchem in Alberton, South Africa, and Glass World in Robertville, South Africa, respectively, for chemical treatments such as de-mineralization and de-proteinization.

\subsection{Methods}

\subsubsection{Extraction of chitin}

Chitin was isolated from the integument of a crab in this investigation. To extract chitin, crab integuments were washed and cleansed with water, followed by room temperature drying, hot air drying (at $50^{\circ} \mathrm{C}$ ), mechanical grinding, and lastly de-mineralization with $0.1 \mathrm{~mol} / \mathrm{L}$ of $\mathrm{HCL}$ at room temperature and de-proteinization with $1 \mathrm{~mol} / \mathrm{L}$ of $\mathrm{NaOH}$ at $90^{\circ} \mathrm{C}$.

\subsubsection{ATR-FTIR Spectroscopy measurements}

The measurements were carried out in Composite Research Laboratory, Durban University of Technology, South Africa. ATR-FTIR spectra were obtained using Perkin Elmer L1050242 $\left(4,000-400 \mathrm{~cm}^{-1}\right)$, and they were collected with a resolution of $4 \mathrm{~cm}^{-1}$ by co-addition of scans for each spectrum at room temperature. The Spectrum10 software compiled with FDA 21 CFR Part 11 regulation for Windows was used to manage the ATRFTIR instrument.

\section{Results and discussions}

The exocuticle, endocuticle of M1, and M2 are the chitin areas of a crab integument, according to the gross morphology illustrated in Figure 1. The extraction of chitin from a crab shell integument with such a complex structure of "chitin-protein-mineral matrix" necessitates a variety of physical and chemical procedures. In addition to washing, cleaning, and drying at room temperature, hot air-drying is an essential physical treatment in the extraction of chitin from crab integument. Evaporation, physico-chemical processes, or a combination of these factors produce "phase changes in a material" during hot air drying. The intricacy of "phase transitions" in M1 and M2 of crab integument complicates hot air drying. The phase of the "chitin-protein-mineral matrix" in the exocuticle-endocuticle of M1 and M2 is changed by hot air drying. The percent yield of chitin from the crab integument is closely connected to phase transitions occurring within the "chitin-proteinmineral matrix" in the exocuticle-endocuticle of M1 and M2. As a result, identifying the relationship between "phase transition" occurring inside M1 and M2 of the crab integument and "chitin yield" is essential. For the first time, phase transitions within the "chitin-protein-mineral matrix" in M1 and M2 are investigated using ATR-FTIR Spectroscopy in this work. The effect of hot air- 

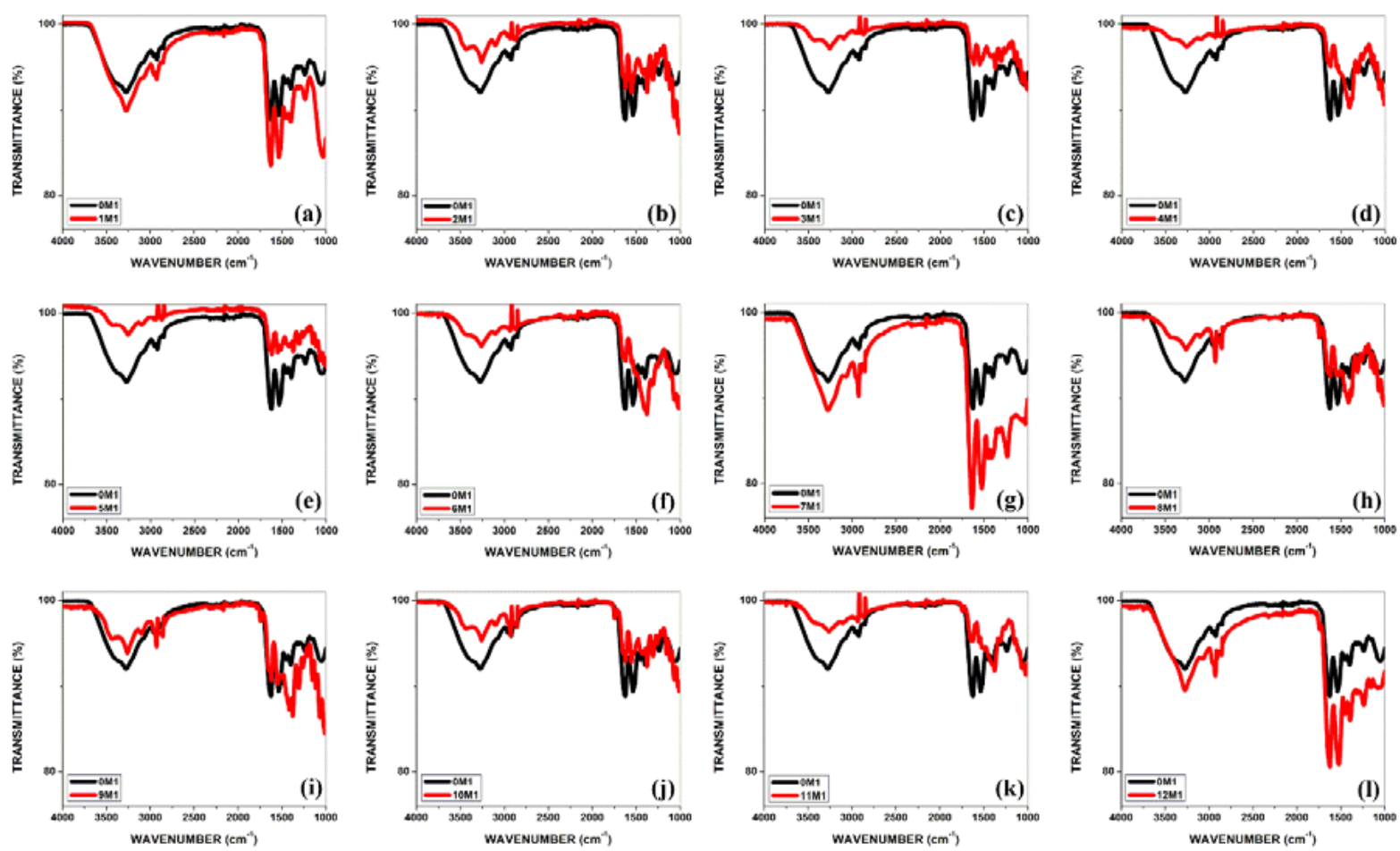

Figure 2: ATR-FTIR spectra for M1: $0 \mathrm{~h}$ vs $1 \mathrm{~h}, 2 \mathrm{~h}, 3 \mathrm{~h}, 4 \mathrm{~h}, 5 \mathrm{~h}, 6 \mathrm{~h}, 7 \mathrm{~h}, 8 \mathrm{~h}, 9 \mathrm{~h}, 10 \mathrm{~h}, 11 \mathrm{~h}, 12 \mathrm{~h}$
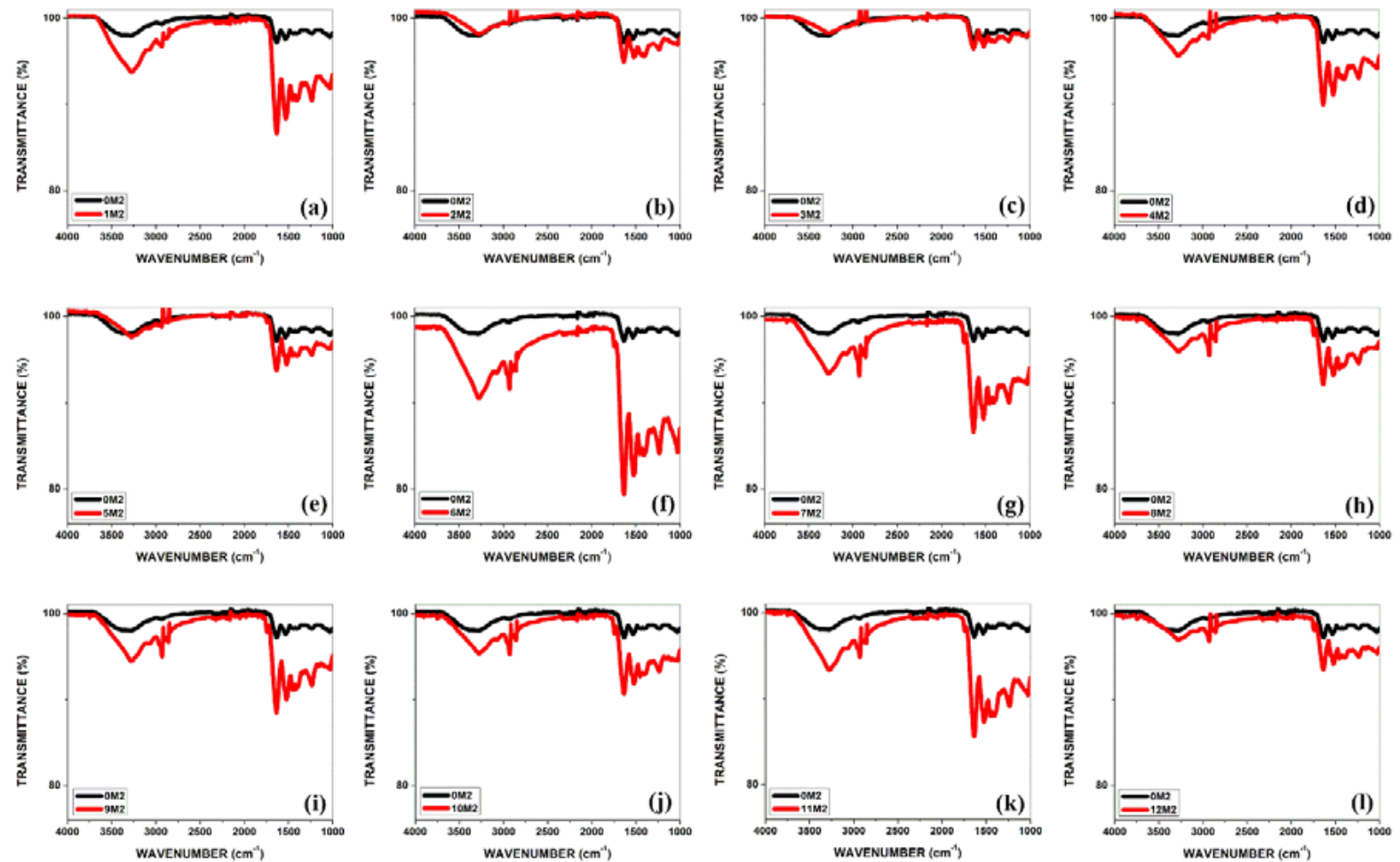

Figure 3: ATR-FTIR spectra for M2: $0 h$ vs $1 h, 2 h, 3 h, 4 h, 5 h, 6 h, 7 h, 8 h, 9 h, 10 h, 11 h, 12 h$

drying on M1 and M2 of the crab integument in relation to percent yield of chitin is also investigated in this paper using ATR-FTIR Spectroscopy.

Let's look at the ATR-FTIR spectra and see how they relate to the "phase transition" and "percent yield" of chitin. Figures 2(a) to 2(l) and 3(a) to 3(1) show ATR-FTIR Spectra for M1 and M2 hot air-dried for $1 \mathrm{~h}, 2 \mathrm{~h}, 3 \mathrm{~h}, 4 \mathrm{~h}, 5 \mathrm{~h}, 6 \mathrm{~h}, 7 \mathrm{~h}, 8 \mathrm{~h}, 9 \mathrm{~h}, 10 \mathrm{~h}, 11 \mathrm{~h}, 12 \mathrm{~h}$, respectively, in contrast to non-hot air-dried 0M1 and 0M2. Comparative ATRFTIR spectra for M1 and M2 hot air-dried for $1 \mathrm{~h}, 2 \mathrm{~h}, 3 \mathrm{~h}, 4 \mathrm{~h}, 5 \mathrm{~h}$, $6 \mathrm{~h}, 7 \mathrm{~h}, 8 \mathrm{~h}, 9 \mathrm{~h}, 10 \mathrm{~h}, 11 \mathrm{~h}$, and $12 \mathrm{~h}$ are shown in Figures 4(a) to 4(1). With regard to ATR-FTIR spectra for non-hot air-dried 0M1, a significant change in the percent transmittance for M1 hot air-dried at $1 \mathrm{~h}, 2 \mathrm{~h}, 3 \mathrm{~h}, 4 \mathrm{~h}, 5 \mathrm{~h}, 6 \mathrm{~h}, 7 \mathrm{~h}, 8 \mathrm{~h}, 9 \mathrm{~h}, 10 \mathrm{~h}, 11 \mathrm{~h}, 12 \mathrm{~h}$ can be seen from 

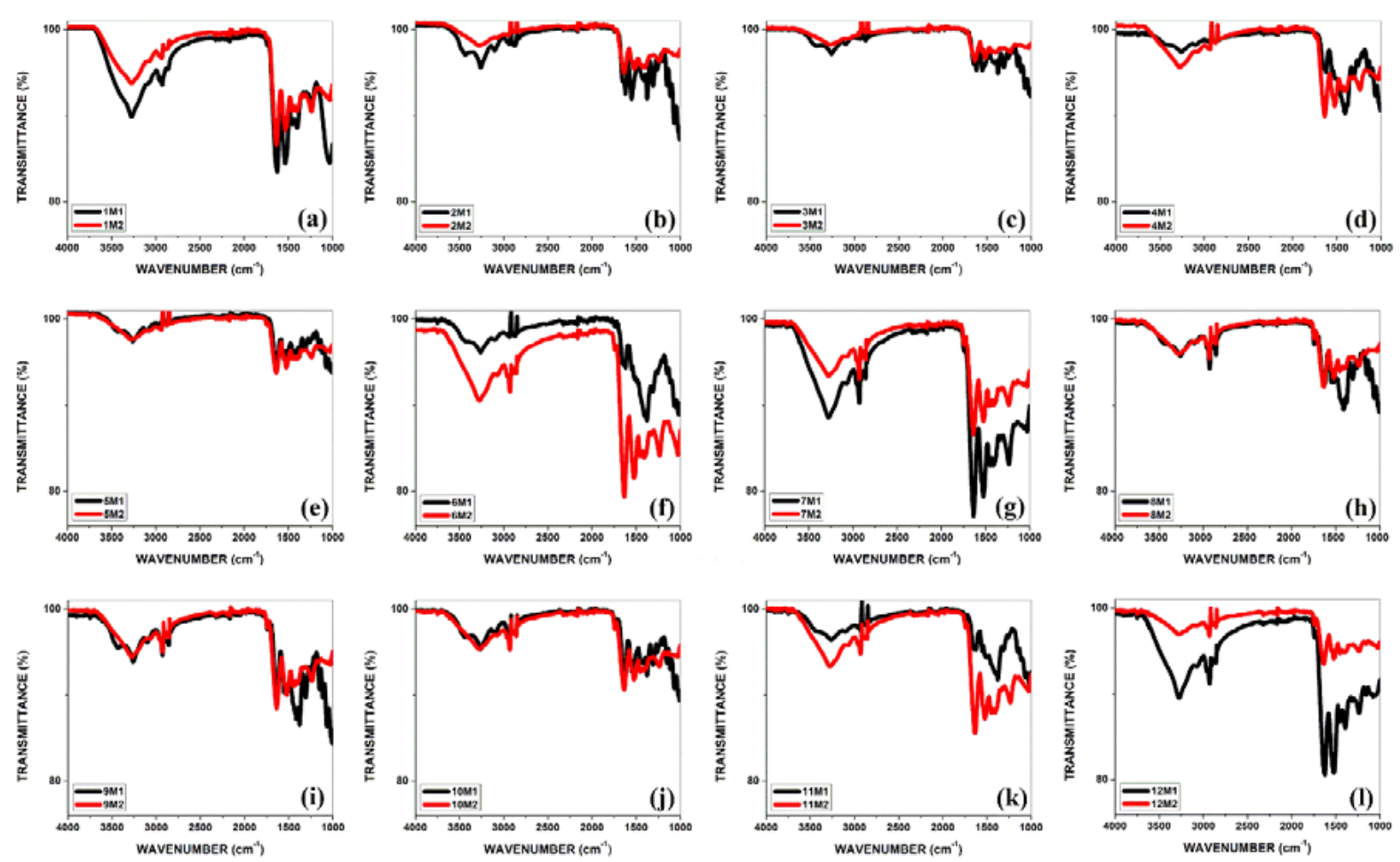

Figure 4: ATR-FTIR spectra for M1@ and M2@1h to 12h (with 1h interval)

Figure 2(a) to Figure 2(1). Figures 3(a) to 3(1) show a change in the percent transmittance for M2 hot air-dried at $1 \mathrm{~h}, 2 \mathrm{~h}, 3 \mathrm{~h}, 4 \mathrm{~h}, 5 \mathrm{~h}$, $6 \mathrm{~h}, 7 \mathrm{~h}, 8 \mathrm{~h}, 9 \mathrm{~h}, 10 \mathrm{~h}, 11 \mathrm{~h}, 12 \mathrm{~h}$ in comparison to ATR-FTIR spectra for non-hot air-dried 0M2. The change in percent transmittance observed for hot air-dried M1 and M2 (in comparison to non-hot air-dried $0 \mathrm{M} 1$ and $0 \mathrm{M} 2$ ) with gradual increase in hot air-drying time, as shown in Figure 2(a) to Figure 2(l) and Figure 3(a) to Figure 3(1), can be attributed to "phase transitions," i.e., intermolecular changes occurring over M1 and M2 as a result of hot air drying. Similarly, the shift in percent transmittance seen in Figure 4(a) to Figure 4(1) for hot air-dried M1 and M2 can be attributed to "phase transitions," i.e., intermolecular changes occurring across M1 and M2 owing to the impact of hot air-drying. Phase transitions are the physical processes that occur when matter changes from one state to another. The phase transitions occurring in M1 and M2 of the crab integument can be linked to changes in percent transmittance. The decrease in the bond length between the molecules, which increases the intermolecular forces of attraction, may be ascribed to a relative rise in percent $\mathrm{T}$ for a specimen. Figures 2(b), 2(c), 2(d), 2(e), 2(f), 2(h), 2(i), 2(j), and 2(k) show an increase in the percent transmittance for hot air-dried M1 when compared to non-hot airdried M1; however, Figures 2(a), 2(g), and 2(l) show a reduction in the percent transmittance for hot air-dried M1 when compared to non-hot air-dried M1. In comparison to non-hot air-dried M1, a rise in percent transmittance for hot air-dried M1 at $2 \mathrm{~h}, 3 \mathrm{~h}, 4 \mathrm{~h}, 5 \mathrm{~h}$, $6 \mathrm{~h}, 8 \mathrm{~h}, 9 \mathrm{~h}, 10 \mathrm{~h}$, and $11 \mathrm{~h}$ revealed an increase in the intermolecular interaction between the "chitin-protein matrix" in M1. Increased intermolecular attraction within the "chitin-protein matrix" will reduce the free mobility of chitin from the "chitin-protein matrix," potentially lowering the chitin percent yield. In compared to nonhot air-dried M1, a drop in percent transmittance for hot air-dried
$\mathrm{M} 1$ at $1 \mathrm{~h}, 7 \mathrm{~h}$, and $12 \mathrm{~h}$ revealed a decrease in the intermolecular interaction between the "chitin-protein matrix" in M1. The free mobility of chitin from the "chitin-protein matrix" will be increased when the intermolecular attraction between the "chitin-protein matrix" decreases, potentially increasing the percent yield of chitin. M2 was subjected to similar tests. A minor overlap of hot airdried M1 ATR-FTIR spectra and non-hot air-dried M1 ATR-FTIR spectra was found in Figure 3(b), 3(c), and 3(e), indicating that hotair drying had little effect on intermolecular interaction within M2. Figures 3(a), 3(d), 3(f), 3(g), 3(h), 3(i), 3(j), 3(k), and 3(l) show that hot air-dried M2 has a lower percent transmittance than non-hot airdried M2. In comparison to non-hot air-dried M2, a drop in percent transmittance for hot air-dried M2 at 1h, 4h, 6h, 7h, 8h, 9h,10h,11h, and $12 \mathrm{~h}$ revealed a decrease in the intermolecular interaction between the "chitin-protein matrix" in M2. As previously stated, M2 is a chitin-rich area devoid of minerals, therefore the magnitude of the percent transmittance drop should be considered. A minimal percent transmittance reduction, as shown in Figure 3(1), reduces the intermolecular attraction between the "chitin-protein matrix," allowing chitin to move freely inside the "chitin-protein matrix," potentially increasing the percent yield of chitin. During the extraction of chitin, a maximum extent of percent transmittance as observed in Figures 3(a), 3(f), 3(g), and 3(k) should possibly release the protein. Furthermore, hot air-dried M1 ATR-FTIR spectra were compared and analyzed with hot air-dried M2 ATRFTIR spectra. Figures 4(a) through 4(c) show a comparison of hot air-dried M1 ATR-FTIR spectra with hot air-dried M2 ATR-FTIR spectra. At $6 \mathrm{~h}$ and $11 \mathrm{~h}$, the percent transmittance for hot air-dried M1 increases in contrast to the percent transmittance for hot airdried M2. At 2h, 3h, 4h, 5h, 8h, 9h, and 10h, proximity in the ATRFTIR spectra for hot air-dried M1 and hot air-dried M2 can also be 
seen. A comparison of percent transmittance for hot air-dried M2 and percent transmittance for hot air-dried M1 at $1 \mathrm{~h}, 7 \mathrm{~h}$, and $12 \mathrm{~h}$ reveals a rise in percent transmittance for hot air-dried M2 (with maximum percent transmittance for $12 \mathrm{~h}$ ). As previously stated, M2 is the chitin-rich region with no minerals; hence, increasing the percent transmittance for hot air-dried M2 while decreasing the percent transmittance for hot air-dried M1 potentially improve the chitin yield.

\subsection{Correlating percent transmittance and percent yield of chitin}

Table 1: Hot air-drying times versus percent yield of chitin

\begin{tabular}{cccc}
\hline Time (hours) & Yield (\%) & Time (hours) & Yield (\%) \\
\hline 1 & 20 & 7 & 75 \\
2 & 25 & 8 & 40 \\
3 & 28 & 9 & 48 \\
4 & 35 & 10 & 55 \\
5 & 44 & 11 & 70 \\
6 & 65 & 12 & 80 \\
\hline
\end{tabular}

Table 1 shows the yield of chitin as a function of hot air-drying periods. The chitin recovered from crab integument that was hot air-dried for 1 hour yielded the least amount of chitin. Chitin isolated from crab integument was hot air-dried for 2 hours, 3 hours, 4 hours, 5 hours, 8 hours, 9 hours, and 10 hours, yielding a low percent yield of chitin (slightly higher than percent yield of chitin extracted from crab integument hot air-dried for $1 \mathrm{~h}$ ).

Furthermore, hot air-drying crab integument for 6 and 11 hours significantly enhanced the percent yield of chitin (in comparison to percent yield of chitin extracted from crab integument hot airdried for $2 \mathrm{~h}, 3 \mathrm{~h}, 4 \mathrm{~h}, 5 \mathrm{~h}, 8 \mathrm{~h}, 9 \mathrm{~h}$ and $10 \mathrm{~h})$. Chitin isolated from crab integument was hot air-dried for 7 and 12 hours, yielding the highest percentage of chitin (in comparison to percent yield of chitin extracted from crab integument hot air-dried for $2 \mathrm{~h}, 3 \mathrm{~h}$, $4 \mathrm{~h}, 5 \mathrm{~h}, 6 \mathrm{~h}, 8 \mathrm{~h}, 9 \mathrm{~h}, 10 \mathrm{~h}$ and $11 \mathrm{~h}$ ). The purity of chitin extracted from hot-air dried crab integument ( $7 \mathrm{~h}$ and $12 \mathrm{~h}$ ) was qualitatively evaluated using ATR-FTIR Spectroscopy and a standard reference chitin sample. When comparing the ATR-FTIR spectra of chitin extracted from crab integument dried for 12 hours and 7hours to the ATR-FTIR spectra of standard reference chitin in Figure 5, it can be seen that the ATR-FTIR spectra of chitin extracted from crab integument dried for 7 hours differs in percent transmittance. As a result, it can be inferred that hot-air drying periods have a substantial impact on the yield and quality of crustacean chitin.

\section{Conclusion}

Minerals, proteins, and chitin make up the integument of crabs, which has a complicated gross morphology. Chitin extraction from such a complicated structure necessitates a combination of physical and chemical procedures. The "percent yield of chitin" recovered from a crab integument is influenced by hot air drying. The "phase transitions" occurring inside the hot air-dried crab integument are shown by the percent transmittance on the ATRFTIR spectra. The effect of hot air drying on the "percent yield of chitin" recovered from crab integument is investigated using ATRFTIR Spectroscopy.

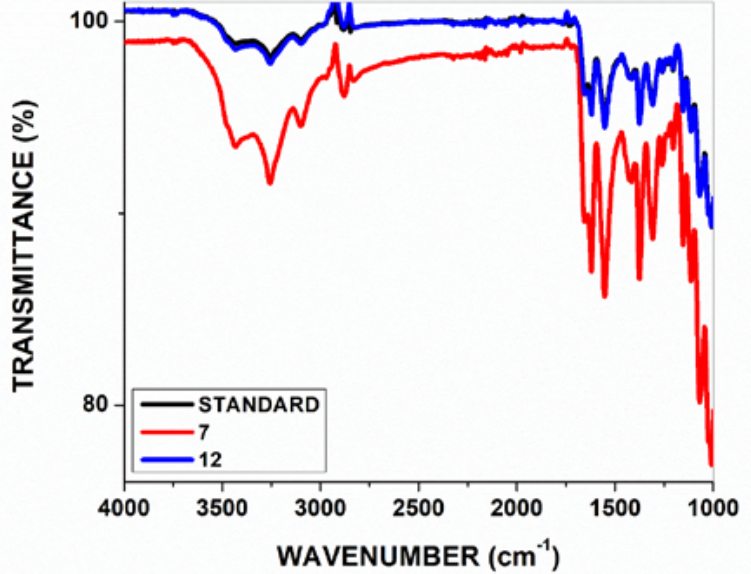

Figure 5: Comparative ATR-FTIR spectra for chitin extracted from hot-air dried crab integuments at $7 \mathrm{hr}$ and $12 \mathrm{hr}$ with a standard reference chitin

\section{Acknowledgements}

The National Research Foundation of South Africa provided a scholarship in the field of composite research to the first author. The authors also like to thank Durban University of Technology in South Africa for providing them with the resources they needed to complete the project. The authors would also want to express their gratitude to all of the writers whose works were cited in the compilation of this paper.

\section{References}

1. Abdou, E.S., Nagy, K.S.A., Elsabee, M.Z., 2008. Extraction and characterization of chitin and chitosan from local sources. Bioresour. Technol. 99, 1359-1367. https://doi.org/https://doi.org/10.1016/j. biortech.2007.01.051

2. Amalraj, A., Jude, S., Gopi, Sreeraj, 2020. Chapter 1 - Polymer blends, composites and nanocomposites from chitin and chitosan; manufacturing, characterization and applications, in: Gopi, Sreerag, Thomas, S., Pius, A.B.T.-H. of C. and C. (Eds.), . Elsevier, pp. 1-46. https://doi.org/https://doi.org/10.1016/B978-0-12-817968-0.00001-9

3. Chen, C., Li, D., Hu, Q., Wang, R., 2014. Properties of polymethyl methacrylate-based nanocomposites: Reinforced with ultra-long chitin nanofiber extracted from crab shells. Mater. Des. 56, 1049-1056. https://doi.org/10.1016/j.matdes.2013.11.057

4. Cuong, H.N., Minh, N.C., Van Hoa, N., Trung, T.S., 2016. Preparation and characterization of high purity $\beta$-chitin from squid pens (Loligo chenisis). Int. J. Biol. Macromol. 93, 442-447. https://doi. org/10.1016/j.ijbiomac.2016.08.085

5. Fan, Y., Saito, T., Isogai, A., 2008. Preparation of Chitin Nanofibers from Squid Pen $\beta$-Chitin by Simple Mechanical Treatment under Acid Conditions. Biomacromolecules 9, 1919-1923. https://doi. org $/ 10.1021 / \mathrm{bm} 800178 \mathrm{~b}$

6. Green, D.W., Perry, R.H., 2007. Perry's Chemical Engineers' Handbook, Eighth Edition.

7. Hisham, F., Maziati Akmal, M.H., Ahmad, F.B., Ahmad, K., 2021. Facile extraction of chitin and chitosan from shrimp shell. Mater. Today Proc. 42, 2369-2373. https://doi.org/https://doi.org/10.1016/j. matpr.2020.12.329

8. Koilparambil, D., Rebello, S., Shanavas, J., 2014. A Simple and Effective Method for Extraction of High Purity Chitosan from Shrimp Shell Waste.

9. Kumari, S., Kishor, R., 2020. Chapter 1 - Chitin and chitosan: origin properties, and applications, in: Gopi, S., Thomas, S., Pius, A.B.T. H. of C. and C. (Eds.), . Elsevier, pp. 1-33. https://doi.org/https://doi org/10.1016/B978-0-12-817970-3.00001-8

10. Kumari, S., Rath, P., Sri Hari Kumar, A., Tiwari, T.N., 2015 Extraction and characterization of chitin and chitosan from fishery waste by chemical method. Environ. Technol. Innov. 3, 77-85. https:// doi.org/https://doi.org/10.1016/j.eti.2015.01.002 
11. Mujumdar, A.S., Devahastin, S., 2016. FUNDAMENTAL PRINCIPLES OF DRYING.

12. Ngoc Cuong, H., Cong Minh, N., Van Hoa, N., Si Trung, T., 2016. Preparation and characterization of high purity-chitin from squid pens (Loligo chenisis). Int. J. Biol. Macromol. 93, 442-447. https://doi. org/10.1016/j.ijbiomac.2016.08.085

13. Pyar Aung, K., Zin Win, S., Lin Thu, S., 2018. Study on Chitin Extraction from Crab Shells Waste, International Journal of Science and Engineering Applications.

14. Rane, A.V., Mathew, L., Kanny, K., Mlowe, S., Revaprasadu, N., Thomas, S., 2019. Attenuated Total Reflectance Fourier Transform Infrared Spectroscopy: A Tool to Determine Reinforcement of Carbon Black in Polylactic Acid Composites. Mater. Perform. Charact. 8, 20190146. https://doi.org/10.1520/MPC20190146
15. Rane, A.V., Yadav, D., Kanny, K., Revaprasadu, N., Thomas, S., 2021. Understanding zones of molecular dimension in poly (lactic acid) composites through Attenuated Total Reflectance Fourier Transform Infrared Spectroscopy: Correlation with Tensile yield Test Measurements. Mater. Perfomance Charact.(Accepted).

16. Roer, R., Dillaman, R., 1984. The Structure and Calcification of the Crustacean Cuticle. Am. Zool. 24, 893-909. https://doi.org/10.1093/ icb/24.4.893

17. Suenaga, S., Nikaido, N., Totani, K., Kawasaki, K., Ito, Y., Yamashita, K., Osada, M., 2016. Effect of purification method of $\beta$-chitin from squid pen on the properties of $\beta$-chitin nanofibers. Int. J. Biol. Macromol. 91, 987-993. https://doi.org/10.1016/j. ijbiomac.2016.06.060

18. Suenaga, S., Osada, M., 2019. Preparation of $\beta$-chitin nanofibe aerogels by lyophilization. Int. J. Biol. Macromol. 126, 1145-1149. https://doi.org/https://doi.org/10.1016/j.ijbiomac.2019.01.006 